The influence of deformation-induced microvoids on mechanical failure of AISI A8-Mod martensitic tool steel

Hadi Ghasemi-Nanesa, Mohammad Jahazi, Majid Heidari, and Tom Levasseur

Citation: AIP Conference Proceedings 1896, 020021 (2017); doi: 10.1063/1.5007978

View online: http://dx.doi.org/10.1063/1.5007978

View Table of Contents: http://aip.scitation.org/toc/apc/1896/1

Published by the American Institute of Physics 


\title{
The Influence of Deformation-Induced Microvoids on Mechanical Failure of AISI A8-Mod Martensitic Tool Steel
}

\author{
Hadi Ghasemi-Nanesa $^{1, \text { a) }}$, Mohammad Jahazi ${ }^{1, \text { b) }}$, Majid Heidari ${ }^{2, c)}$, Tom \\ Levasseur $^{2, d)}$ \\ ${ }^{1}$ Department of Mechanical Engineering, École de Technologie Supérieure, 1100 rue Notre-Dame Ouest, Montréal \\ H3C 1K3, Québec, Canada. \\ ${ }^{2}$ DK SPEC 1060, chemin Olivier, St-Nicolas, G7A 2M8, Québec, Canada. \\ a) Corresponding author: hadi.ghasemi-nanesa.1@ens.etsmtl.ca \\ b) mohammad.jahazi@etsmtl.ca \\ c)majid.heidari@dkspec.com \\ d)tom.levasseur@dkspec.com
}

\begin{abstract}
Tool steels are considered as hard to deform materials since they have a mixture of soft ferritic matrix with hard carbides as secondary particles. In this study, $5 \mathrm{~mm}$ thick plates of AISI A8-Modified tool steel were subjected to cold rolling prior to the quench-temper cycle with the view to investigate the work hardening behavior of this steel during rolling and to reduce the brittleness of the product after the quench-temper cycle. $5 \mathrm{~mm}$ thick samples were rolled 10, 20, 30,40 , and $50(\%)$ under similar conditions and then cut parallel to the rolling direction. Microstructure evolution, deformation-induced microvoids, and hardness evolution as a function of prior deformation were investigated. Electron microscopy was used to investigate the root causes for the formation of microvoids and potential alligatoring failure. The influence of microvoids on mechanical properties after the quench-temper cycle was evaluated through bending tests. Results showed no failure for $50 \%$ cold rolled sample in comparison with fracture for non-deformed sample indicating that prior deformation could be a novel route for improving the in service properties of these alloys. Hardness of 50\% cold rolled after thermal hardening was lower than that for non-deformed sample. The analysis of prior austenite grain size, volume fraction of retained austenite, and volume fraction of carbides for both testing conditions showed that hardness reduction can be related to the presence of microvoids formed in the microstructure during rolling.
\end{abstract}

\section{INTRODUCTION}

Conventional AISI A8 steel is used as cutting tool in a wide range of industries [1]. The possibility of obtaining fully martensitic microstructures with good wear resistance and toughness after the quench-temper (Q\&T) treatment has made this steel a suitable alternative for other tool steels such as D2 which contain higher carbon as well as more expensive alloying elements [2]. Tool steels are known as dual phase steels containing hard carbides and soft ferrite in the as-annealed condition [3-5]. Therefore most of the researches have been focused on improving both strength and toughness by modifying the chemical composition of the alloy and/or the Q\&T cycle [5-8].

Cold deformation is widely used for grain refinement in metallic materials in order to improve mechanical properties [9-12]. Previous studies on the effect of prior deformation on microstructure evolution of hypereutectoid low alloyed steels have shown accelerated spherodization of carbides compared to non-deformed steels during subsequent hardening and tempering cycles [9-12]. Also, prior austenite grain refinement could push down martensite start and finish temperatures and increases the stability of austenite [13-16]. Therefore, microstructure conditioning for obtaining fine prior austenite grains before phase transformation could be an alternative route for increasing the strength and toughness of these high carbide containing steels. In a previous publication [17], authors

Proceedings of the 20th International ESAFORM Conference on Material Forming AIP Conf. Proc. 1896, 020021-1-020021-6; https://doi.org/10.1063/1.5007978

Published by AIP Publishing. 978-0-7354-1580-5/\$30.00 
showed that the application of prior deformation could be a promising way in reducing grain size in AISI A8 tool steel by prior cold rolling thereby bringing improved mechanical properties. Nevertheless, in the high alloyed steel such as AISI A8-Mod which containing primary alloyed carbides, plastic deformability should be investigated seriously since the interface of carbide-matrix or inclusion-matrix is susceptible for crack formation, coalescence and growth leading to failure (e.g. called alligatoring)[18,19] as shown in Fig. 1. During alligatoring failure, material splits in two halves across the plane which is parallel to rolling plane as shown in Fig. 1.

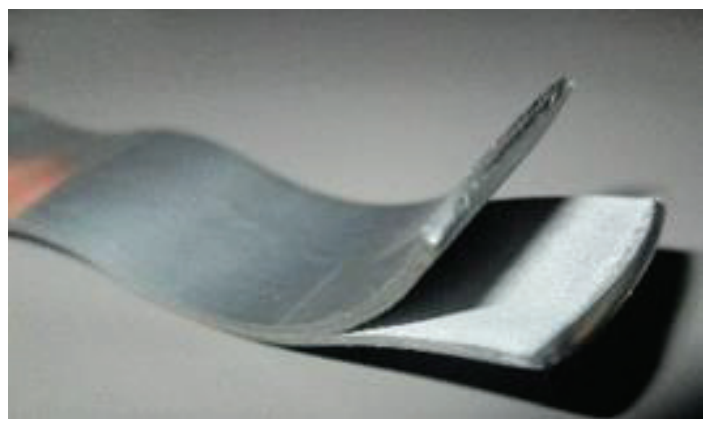

FIGURE 1. Alligatoring failure in the studied AISI A8-Mod tool steel.

In the present work the effect of pre-deformation on the formation of different defects, microstructure evolution, grain refinement, hardness changes, and the extent of martensitic transformation after the Q\&T cycle in AISI A8Mod tool steel is investigated. Adding controlled cold deformation route before quench-temper cycle of tool steels is expected to improve mechanical properties of these alloys and therefore result in higher quality products and longer service life for cutting tools made of these alloys.

\section{MATERIALS AND METHODS}

AISI A8-Mod tool steel plates with nominal composition of C 0.51-Si 0.85-Mn 0.4-Cr 7.44-Mo 1.46-V 0.29W 0.12 (wt \%) and $5 \mathrm{~mm}$ initial thickness were given 10, 20,30, 40, and to 50(\%) reductions in thickness. The rolling machine was a 2-high laboratory milling mills fabricated by Fenn Model: 4-046 with anvil diameters of $100 \mathrm{~mm}$ and maximum rolling pressure of $136 \mathrm{kN}$. For microstructural investigations and hardness measurements, cold rolled samples were polished from their lateral surface parallel to the rolling direction. To avoid artificial effects, etching was not applied on above mentioned samples and only as-polished ones were used for analysis. The as-received material also underwent the same sample preparation procedure for comparison purposes. HITACHI SU-8230 high resolution scanning electron microscope (FE-SEM), PANalytical X-ray diffraction machine model X'Pert Pro, and FutureTech microhardness tester $(200 \mathrm{~g}, 15 \mathrm{~s})$ were employed to evaluate microstructure evolution after cold rolling. Additionally, both as-received and 50\% cold deformed samples were heated up to $1303 \mathrm{~K}$ and held for $30 \mathrm{~min}$ to perform austenitization. After that, conventional quenching (gas quench), and double high temperature tempering (at $773 \mathrm{~K}$ each for holding time of $2 \mathrm{hrs}$ ) cycles were applied in an industrial-sized vacuum furnace in order to compare mechanical properties of both conditions under actual industrial heat treatment conditions. Only quenched and Q\&T samples were prepared for microhardness and microstructure characterization studies. In order to reveal the prior austenite grain boundaries of the martensitic microstructure for both as-received and $50 \%$ cold deformed samples, Vilella etchant along with Olympus LEXT-4200 laser confocal microscope were successfully utilized. To calculate the average grain size of austenite and volume fraction of carbides MIP4.2 image analysis software [20] was used.

\section{RESULTS AND DISCUSSION}

Figure 2(a) shows hardness evolution of AISI A8-Mod tool with the percentage cold rolling. 30\% enhancement in hardness was obtained by only $10 \%$ deformation which was lowered for the subsequent steps up to $30 \%$ deformation. From $30 \%$ to $50 \%$ cold rolled samples, hardness values become close and reach a stable platform. Therefore, it can be said that rolling above $30 \%$ does not contribute significantly to hardness increase and that a saturated deformed microstructure is achieved. On the other hand, Fig .2(b) reveals that above $20 \%$ cold rolling, 
elongated microvoids along with the detachment of the matrix-carbide interface are produced in the microstructure. These elongated microvoids can be connected to each other and lead to alligatoring failure [18]. Although, suitable process parameters optimization showed that alligatoring failure during cold rolling could be avoided by controlling the deformation rate and better lubrication, but the elongated microvoids and detached interfaces between carbides and matrix are still present in cold rolled samples.

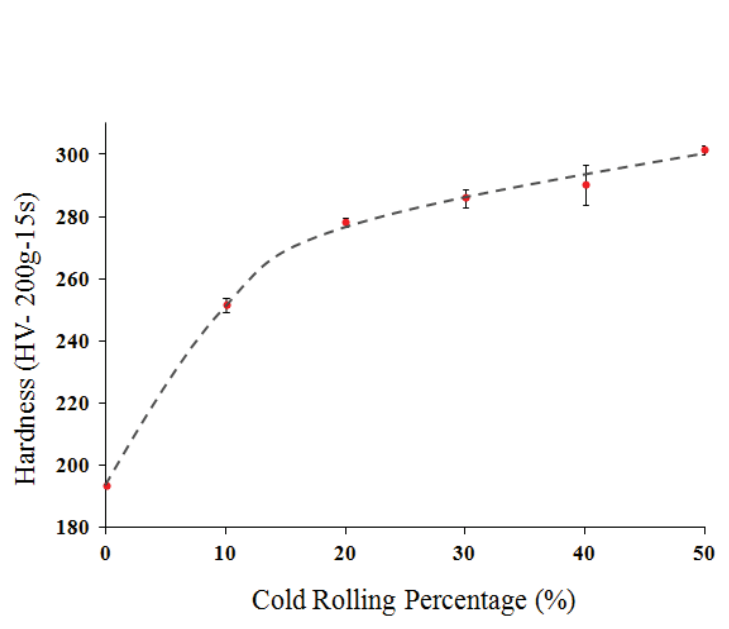

(a)

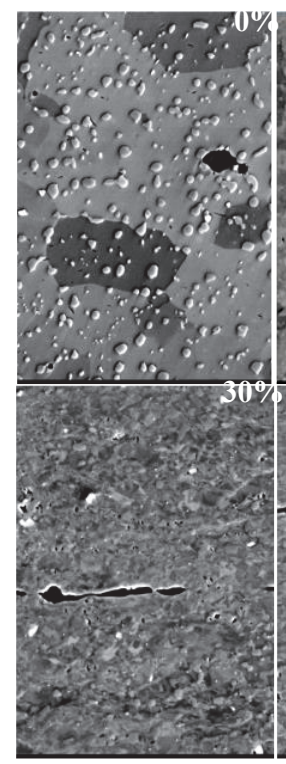

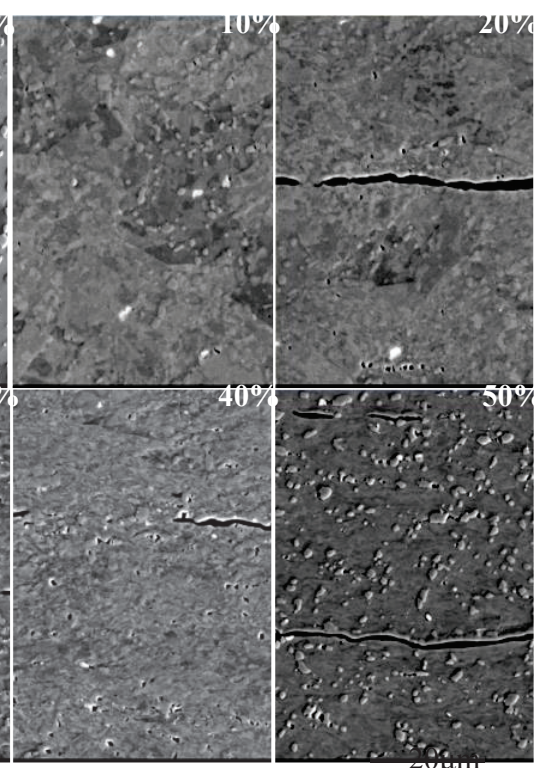

(b)

FIGURE 2. The evolution of hardness with increasing cold rolling percentage, (b) the evolution of microvoids from the as received material to $50 \%$ cold rolled sample

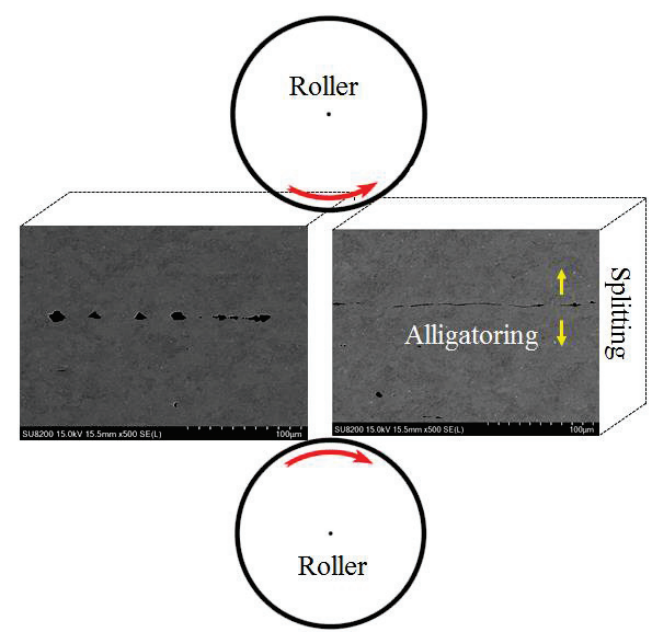

FIGURE 3. The formation of microvoids in a row in $20 \%$ cold rolled sample showing elongation and connection of microvoids to form an elongated void which can be at the origin of alligatoring failure in the subsequent rolling passes.

The mechanism responsible for alligatoring can be understood from Fig. 3 as representative for all deformed samples. This figure illustrates the formation of microvoids in a row and their connections to each other in the lateral surface parallel to the rolling direction after $20 \%$ cold rolling. These findings are in agreement with those of Xu and Daehn who observed alligatoring during cold rolling of a spheroidized AISI 1020, 1045, 1090 steels [18].The formation of elongated microvoids and interface detachment between carbides and matrix during cold rolling could 
be related to the effect of rolling force on the defects present in the initial microstructure since they are present in the matrix in as-received material. Figure 4. (a-b) illustrates the presence of microvoids and microcracks within the matrix and alongside of carbides (yellow arrows) in the as-received material.

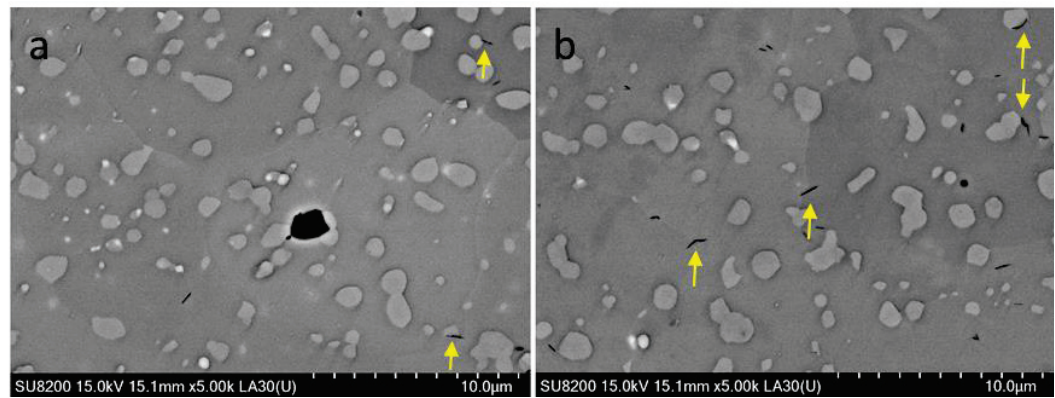

FIGURE 4. The presence of microvoids and microcracks within the matrix and at the interface of carbides in the as-received material prior to deformation, (microvoids in (a), and some microcracks are highlighted by yellow arrows in (a) and (b)).
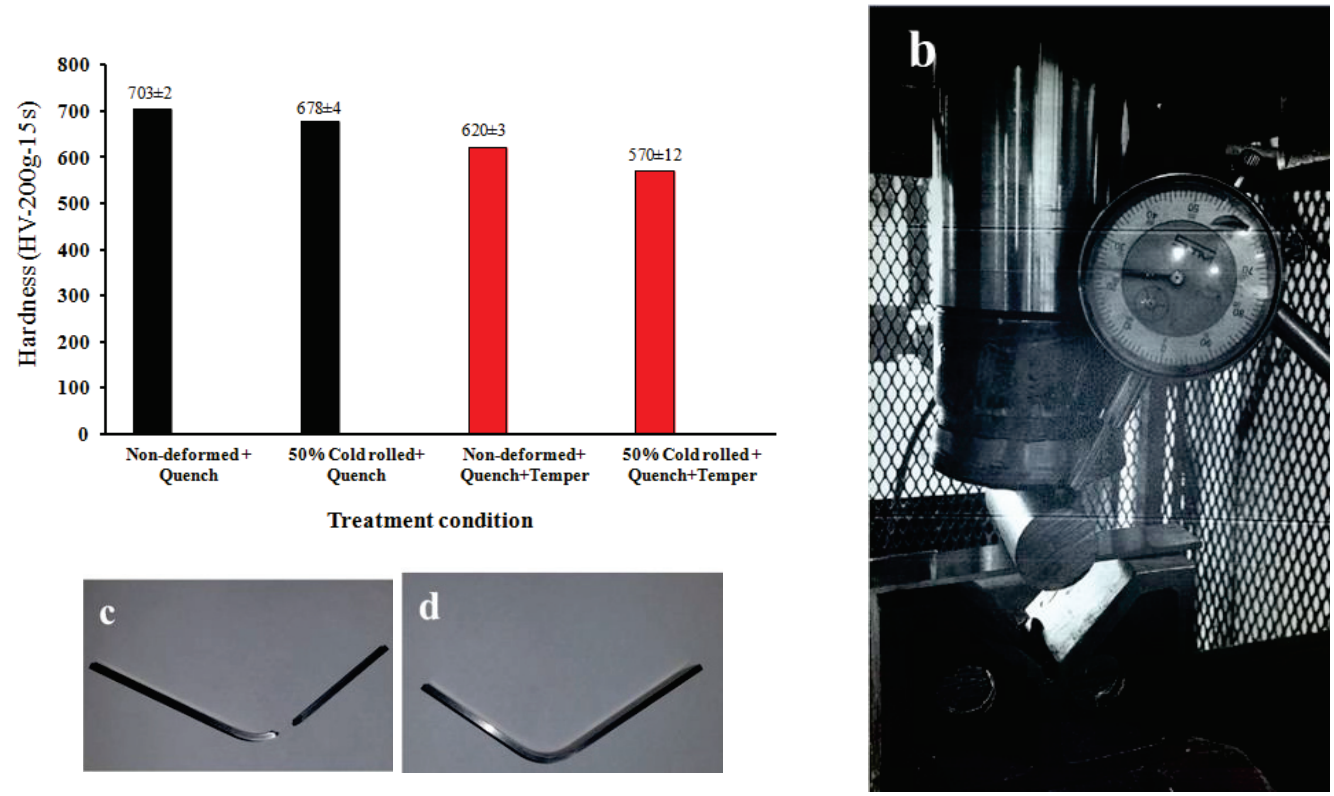

FIGURE 5. (a) Hardness measurements after quench and quench-temper cycles for as-received and 50\% cold rolled samples (b) simple V-type bending test machine, (c) failure in non-deformed sample (d) no failure in $50 \%$ cold rolled sample

Figure 5. (a) shows the hardness of the alloy in the as quenched and after the Q\&T cycle for both as-received (non-deformed) and 50\% cold rolled samples. The results indicate lower hardness values for cold rolled samples in comparison with non-deformed ones.

Simple bending test using compressive loads and V-shape sample holder was carried out on as-received and 50\% cold rolling conditions after the Q\&T cycle (Fig. 5 (b)). The $50 \%$ cold rolled sample did not fracture (Fig.5 (d)) while the non-deformed one fractured during bending as illustrated in Fig. 5(c). This result is very interesting since the $50 \%$ cold sample contains elongated microvoids and detached interface between carbides and matrix and it was expected to fail sooner than the non-deformed. It appears that the increased number of microvoids and detached interfaces have actually had a positive impact on ductility. To validate this finding, further mechanical tests as well as microstructure analyses are required to help better understanding the positive contribution of microvoids on toughness improvement in this alloy. 


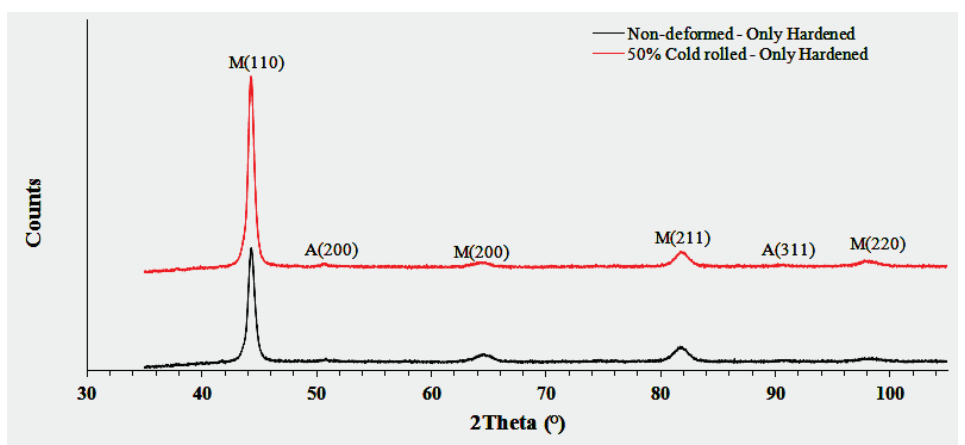

FIGURE 6. X-ray diffraction diagrams of only hardened samples representing martensitic with some retained austenite.
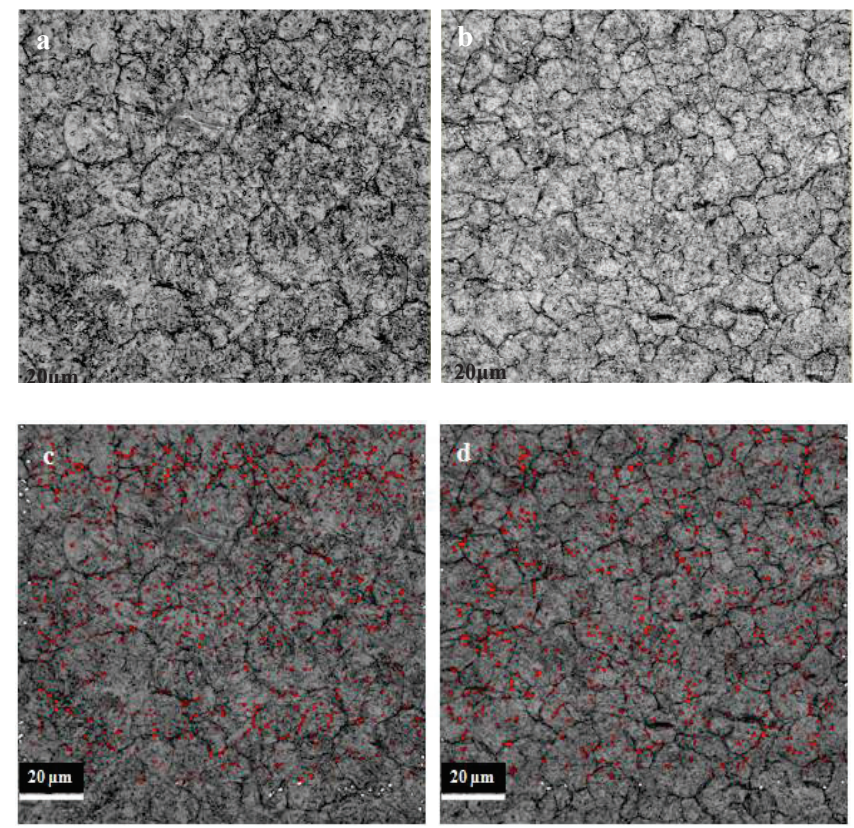

FIGURE 7. Prior austenite grain boundaries of (a) non-deformed and (b) $50 \%$ cold rolled sample after quench cycle (c) volume fraction of carbides for non-deformed and quenched sample, (d) volume fraction of carbides for 50\% cold rolled and quenched sample (red spot shows carbides).

In order to study hardness reduction after quenching in 50\% cold rolled sample compared to the non-deformed and quenched one, the volume fraction of retained austenite, the volume fraction of carbides, and average prior austenite grain size were measured. X-ray diffraction diagrams were utilized in only hardened condition for nondeformed and 50\% cold rolled samples. ASTM E112 standard was followed to calculate the amount of retained austenite. Results indicated the presence of $14 \%$ e retained austenite in the $50 \%$ cold rolled sample compared to $12 \%$ in the non-deformed one. Beswick [3] has reported that a maximum of $1 \%$ and $2 \%$ increment in the volume fraction of retained austenite after 30\% and 64\% cold deformation, respectively in SAE 52100 hypereutectoid steel had no significant impact on hardness value. Therefore, it is possible that reduction in hardness value is not related to the minute difference in the amount of retained austenite. Figure $7 \mathrm{a}-\mathrm{b}$ shows the prior austenite grain size for both nondeformed and $50 \%$ cold rolled sample after quenching cycle. It is evident that for $50 \%$ cold rolled sample more equiaxed grains have been formed in comparison with non-deformed sample. It appears that, the $50 \%$ cold rolled sample has experienced recrystallization during heating from room temperature to austenitization temperature as indicated by the presence of more equiaxed grains after quench hardening cycle. The average grain size calculations for three different images showed $2 \mu \mathrm{m}$ smaller grain size for $50 \%$ cold rolled sample compared to non-deformed sample. However, the observed difference could not be considered significant as Beswick [3] has reported that a 4 $\mu \mathrm{m}$ changes in average prior austenite grain size, didn't change hardness value in SAE 52100 hypereutectoid steel. Additionally, on the same images, the volume fraction of carbides was calculated using image analysis software 
(MIP4.2) (Fig 7.c-d) but no significant change was observed. Only more uniform distribution of carbides is obtained for $50 \%$ cold rolled sample compared to the non-deformed one. Based on the above analysis, it can be said that the observed hardness reduction after $50 \%$ cold rolling is probably due to the higher number of microvoids and detached interfaces between carbides and matrix and the role they seem to play in this regard. However, as mentioned above more work is required to fully characterize and understand this influence.

\section{CONCLUSIONS}

In this study, cold rolling was successfully applied on AISI A8-Mod tool steel before quench-temper cycle. Simple bending test results showed more ductility for 50\% cold rolled sample compared to non-deformed specimens. The final hardness was lower for the $50 \%$ cold rolled samples in spite of smaller grain size and no reduction in the volume fraction of carbides. The higher number of microvoids and detached interfaces between carbides and matrix appears to play a role in the hardness reduction and improved ductility observed during mechanical testing.

\section{ACKNOWLEDGMENTS}

The authors would like to thank the National Sciences and Engineering Research Council of Canada (NSERC), MITACS Canada for their support and financial contribution. The authors also appreciate the collaboration of DK SPEC Inc. for providing experimental and materials, and Olympus for privileged access to advanced LEXT confocal microscope.

\section{REFERENCES}

1. M. Heidari, C. Blais, R. Hernandez, T. Levasseur, Materials Science and Technology-association for iron and steel technology 4, 2555-2562 (2013).

2. G. Roberts, G. Krauss, R. Kennedy, Tool Steels: 5th Edition (ASM International, Materials Park, OH, USA1998).

3. J. Beswick, Metall.Trans. A 15, 299-306 (1984).

4. J. Chakraborty, D. Bhattacharjee, I. Manna, Scripta Mater. 61, 604-607 (2009).

5. S. Li, L. Deng, X. Wu, Cryogenics 50-8, 433-438 (2010).

6. S. G. Singh, J. Singh, R. Singh, H. Singh, Int. J. Adv. Manuf. Technol. 54, 59-82 (2011).

7. D. Das, A.K. Dutta, K.K. Ray, Mater Sci Eng A527-9, 2182-2193(2010).

8. D. Das, A.K. Dutta, K.K. Ray, Philos. Mag. Lett. 88, 801-811(2008).

9. M. Tokizane, N. Matsumura, K. Tsuzoki, T. Maki, I. Tamura, Metall Trans A 133, 1379-1388(1982).

10. E.A. Chojnowski and W.J.McG. Tegart, J. Met. Sci. 2, 14-18 (1968).

11. H.S. Joo, S.K. Hwang, H.M. Baek, Y.T. Im, H. Son, C.M. Bae, J. Mater. Process. Technol. 216, $348-356$ (2015).

12. H. Azizi-Almizani, M. Militzer, W. J. Poole, Metal. Mater. Trans. 42A, 1544-1557 (2011).

13. J.R.C. Guimarães, Scripta Mater. 57, 237-239 (2007).

14. J.R.C. Guimarães and J.C. Gomes, Acta Metall. 26, 1591-1596 (1978).

15. S.-J. Lee and Y.-K. Lee, Mater. Sci. Forum 475-479, 3169-3172 (2005).

16. H.-S. Yang and H.K.D.H. Bhadeshia, Scripta Mater. 60, 493-495 (2009).

17. H. Ghasemi-Nanesa, I. Cazic, M. Jahazi, Collected Proceedings, "Influence of pre-deformation on microstructure evolution and hardness of AISI A8 tool steel", in UFGNSM-2015, Collected Proceedings, code 2019, pp. 1-6.

18. L. Xu and G. S. Daehn, Metal. Mater. Trans. 25A, 589-598 (1994).

19. D. Kwon and R.J. Asaro, Metal. Mater. Trans. 21A, 589-598 (1990).

20. Nahamin Pardazan Asia, MIP (Metallographical Image Processing), December, 2016, Iran, < $\underline{\text { http://en.metsofts.ir/> }}$ 